errors of metabolism, the knowledge that genes direct the production of specific enzymes and shrewd clinical observation followed. By 1950 the development of molecular biology enabled medical genetics to flourish. Here Weatherall, a participant in recent progress, stresses that curiosity-driven research was the major promoter.

Weatherall concludes with a return to the patient. He notes that despite the new biology, each of us is unique and influenced not only by ordinary heredity but also heredity mediated through tradition and the transfer of information through non-genetic routes from one generation to the next. Therefore, there is no reason why the new biology should have a dehumanizing effect on doctors of the future. Ethical issues rapidly accumulate because of scientific high-technology medicine. The definition of death, in vitro fertilization, and codes for organ transplantation must be founded on firm science, or "when this is not possible, on a consensus reached only after a completely open debate between doctors, courts, and public." Genetic manipulation makes the definition of the value of life even more difficult. Ethical questions arise with the 'selection' made possible by prenatal identification of genetic diseases. The transplantation effect of somatic gene therapy is less problematic than germ-line therapy that could pass a 'foreign' gene on to future generations. At the other end of life, public debate should help determine when and to what extent to apply the benefits of high-tech practice to ageing populations. In the end, "the sheer complexity and unpredictability of the manifestations of illness is responsible for the notion of medicine as an art." At that point "simple kindness and empiricism must take over." Weatherall predicts that "while there are still patients to treat, medicine is likely to remain very much an art."

This thesis and its annotated history rank with those of Rosemary Stevens and Paul Starr. Physicians, medical students, journalists, legislators and their health aides, anthropologists and biological scientists will appreciate its reasoned call for patience with 'the silent art'. The reviewer yearns for a broader dissemination of his instructive message through a televised series such as those by Lewis Thomas and David Attenborough.

President Emeritus American Board of Internal Medicine 200 SW Market Street, Suite 1950 Portland, Oregon 97201, USA

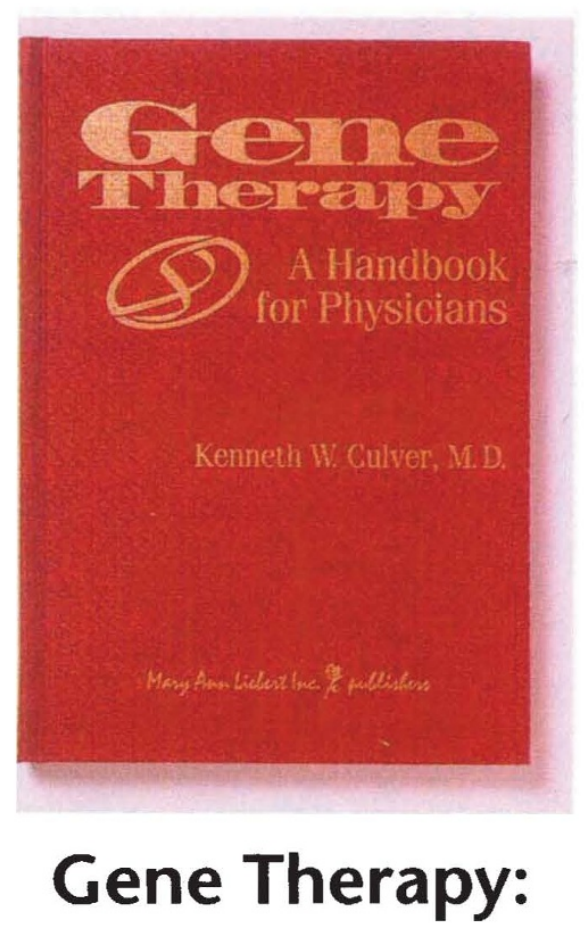

\section{A HANDBOOK FOR PHYSICIANS}

\section{BY KENNETH W. CulVER \\ Mary Ann Liebert Inc., 1994 \$Price}

REVIEWED BY JAMES J. FERGUSON JR

Some years ago Alvin Toffler, in his popular book Future Shock, offered the thesis that the social and technical complexities imposed by progress may be overwhelming our capacity to deal with them. Kenneth Culver's book helps us deal with such complexities of progress in the burgeoning field of gene therapy, and it does so with a flair. And Culver more than implies that we ain't seen nothin' yet! As a front-line participant in pioneering and continuing studies in gene therapy, Culver has the credentials to write on the subject. His efforts to this end are most welcome.

I'm reminded of a friend describing her first explorations on the Internet, chatting electronically with an unknown correspondent. When she typed "I've never done this before," the message purred back "I'll be gentle." Culver is mercifully gentle, leaving the unraveling of technical complexities to the extensive bibliography he provides. His overview of the background history and principles of the discipline is lucid, with special appeal to the novice reader. Its depth suffers only from the space limitations reasonably imposed by an overview of this type.

This is a 'niche' book, which targets the mid- and late-career physician whose every intuition insists there is something of overwhelming importance under way in medical science, but who isn't quite sure how even to frame a coherent question about it. The term 'Handbook' is something of a misnomer. Rather, Gene Therapy presents a concise vignette of an infant field that is progressing so rapidly that books can only describe its past rather than its present. The book was, in fact, published in 1994, probably with a publisher's deadline in late 1993. The intervening year surely has provided follow-up information on the provocative clinical initiatives mentioned in the book. New and equally tantalizing leads have obviously emerged since its publication. For example, recent progress in the application of gene therapy in utero begs timely updating, as does the inevitability of considering germ-line therapy. Will there be a sequel? We hope so.

The scope of this brief book (117 pages) is inviting. It effectively reviews the momentous developments that have made gene therapy technically possible and then explores and critiques the methodologies now used for the insertion of foreign genes into somatic cells. Culver appropriately points to the complexity and difficulty in effecting efficient gene transfer, currently the major impediment to progress in gene therapy. Starting with the pioneering treatment in 1990 of two desperately ill children with adenosine deaminase deficiency, his book recounts subsequent forays into this brave new world of somatic cell gene therapy in examples of familial hypercholesterolaemia and cystic fibrosis. There follows an outline of current, pending, and proposed applications of gene therapy to an extensive series of hereditary, immunological, hormonal and infectious disorders. Finally, in describing work in progress in the treatment and prevention of neoplastic diseases, the author displays the true promise and wonder of gene therapy in a dimension which wasn't even imagined a decade ago.

Does Culver's book have shortcomings? Certainly, but not many. Professionals in the field will not be sated by its content, but those of us on the sidelines have much to gain from reading it. Gene Therapy points to a future which may fall short of our expectations, or that may arrive too late for our needs, but nevertheless a future which we must comprehend and assimilate.

\section{Professor Emeritus \\ University of Pennsylvania \\ Chevy Chase, Maryland}

